\title{
What Impact has SARS-CoV-2/Covid-19 Pandemic on Healthcare Workers (HCWs) Mortality \& Infections across 36 states \& union territories of India? How to prevent mortality \& morbidity of HCWs?
}

Dr Piyush Kumar ( $\nabla$ drpiyush003@gmail.com )

Government of Bihar https://orcid.org/0000-0001-9857-478X

\section{Research Article}

Keywords: Healthcare workers (HCWs), covid-19 infection, safety, pandemic, Mortality, Doctors, Nurses, Death, India

Posted Date: May 19th, 2021

DOI: https://doi.org/10.21203/rs.3.rs-538781/v1

License: (c) (i) This work is licensed under a Creative Commons Attribution 4.0 International License. Read Full License 


\section{Abstract \\ Background}

The ongoing coronavirus pandemic caused by SARS-CoV-2/covid-19/novel coronavirus is an acute infectious communicable disease spreading mainly via respiratory, eye, mouth and other possible routes from person to person as well as through contact with infected non living objects. The pandemic has massively increased healthcare systems burden due to high hospitals admission rate, infection rates, morbidity, and mortality. QALY (quality adjusted life years) \& DALY (disability adjusted life years) are also important for consideration of impact of this pandemic. The healthcare systems is under constant massive pressure to halt the spread of the novel coronavirus \& a huge part of this responsibility is being shouldered by frontline health care workers including doctors, nurses, paramedical workers, ASHAs and Anganwadi services etc. Hence HCWs are inevitably and routinely exposed to the virus hence naturally are at high risk of infection, possible mortality \& morbidities.

\section{Objectives}

The key objective is to find out impact of SARS-CoV-2/Covid-19 Pandemic on Healthcare Workers (HCWs) Mortality \& Infections across 36 states \& union territories of India. What are the reasons of mortality and morbidity \& How to prevent mortality \& morbidity of HCWs? Methodology/settings \& design (search strategy-Research

\section{Methods):}

Several databases were searched for deaths of HCWs in India between January 2019 and 18th May 2021, including MoHFW website, PUBMED, WHO COVID-19 database, COVID-19 Study Register, and Google scholar. The search terms used were: "healthcare providers / health care workers/nurses- death in India due to COVID-19", "SARS-CoV-2", "Coronavirus," using Google search. Whatever data obtained is tabulated.

\section{Results}

There is increase in mortality of HCWs in India. The data is not available completely in my search. Beside increased death I have found a lot of controversy and questions raised on the issue of this data. There is lot of discrepancy in data given by Government and other sources. According to the Indian Medical Association, 244 doctors have lost their lives due to Covid in the second wave. Of them, 50 deaths were recorded on Sunday. The highest number of fatalities have been reported from Bihar (69) followed by Uttar Pradesh (34) and Delhi (27). 


\section{Conclusion}

The government and other agencies should collect and provide the data publicly so that it can be analysed by different sections of researchers to give feedback which will help in making policies helpful to protect HCWs. A large number of medical staffs are infected due to the lack of adequate protection. Currently, the COVID-19 pandemic is growing day by day with lack of essential facilities for treatment. Some experts have warned of a possible third wave of COVID-19.

\section{Background}

The ongoing coronavirus pandemic caused by SARS-CoV-2/covid-19/novel coronavirus is an acute infectious communicable disease spreading mainly via respiratory, eye, mouth and other possible routes from person to person as well as through contact with infected non living objects.[i] The pandemic has massively increased healthcare systems burden due to high hospitals admission rate, infection rates, morbidity, and mortality. QALY (quality adjusted life years) \& DALY (disability adjusted life years) are also important for consideration of impact of this pandemic. The healthcare systems is under constant massive pressure to halt the spread of the novel coronavirus \& a huge part of this responsibility is being shouldered by frontline health care workers including doctors, nurses, paramedical workers, ASHAs and Anganwadi services etc. Hence HCWs are inevitably and routinely exposed to the virus hence naturally are at high risk of infection, possible mortality \& morbidities. There is a growing concern and sense of fear among healthcare workers of India erupting from the news regarding daily death of HCWs due to covid19 infections acquired at workplace, violence \& struggle at workplace, scarcity and supply of inferior quality PPE[ii] In the early phase during $2020 \mathrm{HCW}$ s are seen using bed sheet, raincoats etc as PPE kit for protection due to scarcity of PPE kit see figure 3. The healthcare workers are under undue constant stress due to several factors added to this which may affect mental health as well as physical and social health status of care providers.

On March 11, 2020, the World Health Organization announced covid-19 as a pandemic and within no time infection first discovered in china (december2019), Hubei province reached India in January 2020. The health work force in Bihar is struggling since then with strict regulation and legal bindings as well as scare resources added with regular death of workers and patients creating stress and panic. In the current year 2021 and last year 2020 healthcare workers have had a high rate of infection hence for safety of healthcare workers it's important to ensure that procedures, equipment and training are fully protective. At the same time long term, nursing, and resident care providers should have guidance for long term care, nursing homes, assisted patient living facilities and other resident care facilities such as ICU/covid-19 wards for protective measures to reduce the high incidence and prevalence of covid-19 cases and deaths of workers. Emergency services must have critical infrastructure to be able to function properly including law enforcement, fire and violence safety etc. This time last year in 2020 India was under lockdown phase, many theories about India's surprisingly low rates of Sars-CoV-2 infection included variety of factors including hot weather, natural immunity, heard immunity, robust health system, highly qualified doctors and the country's high proportion of young people; some also attributed it to the country's harsh 
lockdown. India was doing so well that in megacities like Mumbai and Delhi, officials had begun dismantling temporary COVID-19 facilities. Comparing it to current scenario in April 2021, cases and deaths are soaring. The shortage of beds and space is so acute that people are dying in car parks and other places while waiting to be admitted in hospitals. Daily rates are currently over 300,000 , the world's highest-ever daily infection rate. The SARS-CoV-2/COVID-19 pandemic is still going on and globally as well as in India particularly healthcare system is overstressed with this new burden added with previous NCD (non communicable diseases) \& CD (communicable diseases). The First human case of this global pandemic was reported from Wuhan city of China in December 2019. The first case of COVID-19 in India was found in January 2020. Today India is having more than 2 lakh cases per day and thousands of deaths daily due to this pandemic. The situation is very worse as compared to previous year and is worsening day by day due to several factors.[iii] Added to previous global burden of NCDs (non communicable diseases) \& other communicable diseases this new burden of covid-19 pandemic have put a stress on already overstressed health system of India particularly poor states like Bihar.[iv] The delivery of health services is of utmost importance and prime concern in India particularly poor states like Bihar due to high population load with limited resources, poor infrastructure and huge demand on healthcare system. The Healthcare workers (HCWs) are particularly vulnerable group hence they needs essential attention and consideration.[v]

Data show that HCWs account for $8 \%$ of global COVID-19 cases, and that their risk of getting infected is more than triple the risk faced by most of population, the ones they are trying to protect. Globally, $70 \%$ of the health workforce is made up of women as nurses, midwives and community health workers. Progression in this sector, however, is not guaranteed if you are a woman. There are stereotypes and barriers that deter women from moving up the career ladder or getting engaged in the decision-making process. Five weeks ago, out of the 1.3 million health workers that had been infected with COVID-19, 68\% were women.[vi]

The SARS-CoV-2 pandemic had presented a challenge even for developed healthcare systems around the world. [vii] A sense of fear gripped the whole world due to pandemic and India is not an exception. The scarce healthcare resources including manpower, infrastructure, transportation (ambulance services) etc. have been largely deployed to tackle the situation of pandemic of Covid-19. India was already shortstaffed in health care. India had about 17 active health workers - doctors, nurses and midwives - per 10,000 people, according to the World Health Organization. That is far below the W.HO.'s threshold of 44.5 trained/skilled health workers per 10,000. The distributions are unequally concentrated in urban centers. About 40 percent of health care providers work in rural village areas, where more than 70 percent of India's population lives. Bihar, one of India's poorest states, has only 0.24 beds per 1,000 people, less than one-tenth of the world average[viii]

This shift \& covid-19 pandemic has tremendous and detrimental effects on HCWs. The healthcare workers of India as well as Bihar are getting frequently infected leading to death of thousands of healthcare workers till date. Although there are several guidelines issued for precaution and safety at workplace by WHO (world Health Organization) \& several accredited organizations but a protective and 
supportive approach from local management and governance is need of the hour. It seems that there is failure of protective and preventive measures at workplace documented and evidenced by several deaths of healthcare workers. Consequently it is apparent from above scenario to ensure the health and safety of healthcare workers in order to control the outbreak and decrease panic and fear among healthcare workers.

[i]https://doi.org/10.22541/au.162083035.55581251/v1

[ii]https://www.telegraphindia.com/india/bihar-doctor-deaths-blamed-on-inferior-ppe/cid/1788730

[iii]https://covidscholar.org/article/608d13484e85066fbf2f1797

[iv]https://doi.org/10.21203/rs.3.rs-348841/v4

[v]https://www.researchsquare.com/article/rs-360551/v1

[vi]https://www.euro.who.int/en/countries/albania/news/news/2021/3/women-at-the-forefront-of-thecovid-19-response-in-albania-we-will-keep-fighting-until-this-virus-is-defeated

[vii]https://europepmc.org/article/ppr/ppr304897

[viii]https://www.nytimes.com/2021/05/18/world/asia/india-covid-doctors-medical-workers.html

\section{Objectives And Goals}

The key objective is to find out impact of SARS-CoV-2/Covid-19 Pandemic on Healthcare Workers (HCWs) Mortality \& Infections across 36 states \& union territories of India from January 2020 when first covid-19 case was found in India upto $18^{\text {th }}$ may 2021 . What are the reasons of mortality and morbidity \& How to prevent mortality \& morbidity of HCWs? How to prevent mortality \& morbidity of HCWs? How to increase safety and healthy lifestyle adoption among healthcare workers \& providers to reduce mortality and morbidity?

\section{Methodology}

\section{Methodology/settings \& design (search strategy-Research Methods):}

Several databases were searched for deaths of HCWs in India between January 2019 and $18^{\text {th }}$ May 2021 , including MoHFW website, PUBMED, WHO COVID-19 database, COVID-19 Study Register, and Google scholar. The search terms used were: "healthcare providers /health care workers/nurses- death in India due to COVID-19", "SARS-CoV-2", "Coronavirus," using Google search. Whatever data obtained is tabulated.

\section{Result}


In February2021, the health ministry claimed in the Rajya Sabha that a total of 162 doctors, 107 nurses and 44 ASHA workers had died in the line of Covid-19 duty up till that point see Table 3-. However, the Indian Medical Association claimed last week that at least 734 doctors alone had died of Covid-19[i]

The Ministry of health \& family welfare Government of India on 15 September 2020 publicly detailed about HCWs death through a statement released by PIB (press information bureau) Gol under headingCOVID-19 Fatalities amongst Healthcare Workers stating that: see Table-4-

Health is a subject of concerned states. Hence such data is not maintained at Central level by Ministry of Health and Family Welfare (this statement seems to say that MoHFW is not having any such data collected and probably deaths of HCWs are not being monitored at central level by Gol) However, database of those seeking relief under the "Pradhan Mantri Garib Kalyan Insurance Package" is maintained at national level. Ministry of Health and Family Welfare provided guideline on Infection Prevention and Control practices to the State Governments. Training was conducted for all the States in the month of March 2020. A training plan was also conveyed to States to complete training up to district level by $20^{\text {th }}$ March 2020.Training on Infection Prevention and Control was also made available for all categories of healthcare workers on the iGoT platform.

States were asked to constitute Infection Prevention and Control committees. Hospitals were also to identify a nodal officer who will monitor the healthcare workers and review their exposure status. High risk exposures are placed under quarantine for 7 days (is this perfect as per protocols?). Based on their exposure/clinical profile such doctors, nursing officers and other health workers, a decision shall be taken by the Nodal Officer/Head of the Department (or his appointed Sub-committee) for further period of one week. An advisory for managing health care workers working in COVID and Non-COVID areas of the hospital was issued by Ministry of Health and Family Welfare on $18^{\text {th }}$ June, 2020.

Guidelines on rational use of PPEs for hospital and community settings (including front line workers) were issued on 24.03.2020 (no available data of PPE). These guidelines followed a risk based approach and recommended type of PPE that needs to be used in high and low risk areas.

The healthcare workers were provided with hydroxychloroquine for prophylaxis and prevention of infection (no scientific study or explanation available)

N-95 masks and triple / double ply masks were brought under price control.[ii](Data about availability is missing)Export of PPEs, N 95 masks, triple/ double ply medical masks, goggles and visors were banned till such time we were self-reliant.

In another search result the following statement of Gol is found as follow:

GOVERNMENT OF INDIA

MINISTRY OF HEALTH AND FAMILY WELFARE 
RAJYA SABHA

UNSTARRED QUESTION NO 85

TO BE ANSWERED ON $2^{\text {nd }}$ February, 2021

DEATH OF HEALTHCARE WORKERS DUE TO COVID-19

\section{SHRI BINOY VISWAM:}

The Minister of Health and Family Welfare is pleased to state:

(a) The number of healthcare staff, including doctors, nurses and ASHA workers who have been affected by and died due to COVID-19;

(b) Whether the Ministry has collated any data from the State Governments regarding the same;

(c) Whether the data presented by the Indian Medical Association regarding the number of healthcare workers who have died due to COVID-19 has been taken note of by the Ministry and any follow up verification of the same done?

ANSWER-

THE MINISTER OF STATE IN THE MINISTRY OF HEALTH AND

\section{FAMILY WELFARE}

(SHRI ASHWINI KUMAR CHOUBEY)

(a) \& (b): Based on the intimations received from the states on Healthcare staff, including Doctors, Nurse and ASHA worker who have been affected and died from COVID-19 (As per Pradhan Mantri Garib Kalyan Package (PMGKP: Insurance Scheme) is placed below in table 3:

\section{Table-3}

\begin{tabular}{|lll|}
$\begin{array}{lll}\text { No. of Healthcare Staff died due to COVID-19 } \\
\text { (as on 22.01.2021) }\end{array}$ & \\
\cline { 1 - 3 } Doctors & Nurses & ASHA workers \\
& 107 & 44 \\
\hline
\end{tabular}

(c): The process of insurance disbursement has been de-centralized under the PMGKP: Insurance Scheme. Accordingly, the verification of a person affected and died to COVID-19 vests with the concerned State Governments/Central Government authorities. 
The necessary certification for claims is done by Healthcare Institution/ organization/ office where the deceased was an employee of / engaged by the institution. They submit the documents to the Competent authority for State/UT, or the Competent authority for Central Government, Central Autonomous / PSU Hospitals, AllMS, INIs and Hospitals of other Central Ministries, as the case may be. The Competent Authorities then forward and submit claim to the insurance company.

The results and reference found through another extensive research on Google search etc is given in table-5

[i]https://scroll.in/article/992634/amidst-intense-covid-19-second-wave-indian-government-insurancecover-for-health-workers-has-lapsed

[ii]https://pib.gov.in/PressReleasePage.aspx?PRID=1654454

\section{Discussion}

India needs to develop a safety protocol with all important stakeholders of health department and other concerned authorities such as police department to establish Intersectoral multidepartment approach for solving issues, building safety protocol with division \& statement regarding responsibility of Employer and Health care worker as well as other concerned department and authorities. A proper classification of safety protection, hazards and involved risk See Table 1 is presented for discussion and use.

\section{The country also needs:}

- Establishment of Central advisory committee and research wing at state level to keep health workers updated about latest information and guidelines of treatment as these things are changing continuously \& almost daily with new findings. Use of reliable and highly accredited sources such as WHO, ICMR, MoHFW, CDC , peer reviewed publications of reputed science journals etc. for providing information to healthcare workers can be utilized to explain basic factsheet of covid-19 virus and disease through IEC etc., incubation period \& transmission through droplet, aerosol, contact and other possible routes (stool etc).

- Risk assessment of workplace to be carried out by analyzing various parameters related to infection \& Stepwise approach instead of high technical letters to demonstrate steps of worker protection in real scenario by experts giving clear description and vision on worker protection and IPC (infection prevention and control).

- Special capacity building \& training of healthcare workers involved particularly in invasive and aerosol generating procedures to protect themselves as well as training of healthcare workers for using PPE, respirators, ventilators etc as well as regarding decontamination of medical and surgical equipments. Health promotion and motivation of healthcare workers by traditional yoga, moral and financial support as well as providing working environment with adequate rest hours to ensure good health added with entertainment programs to divert anxiety. 
- The government and policy makers should ensure making and enforcement of safety/preventive/protective protocolsto ensure safety at workplace by reducing exposure to SARSCoV-2 infection sources by using PPE \& WASH measures etc. Creating awareness \& providing training to health care workers for infection control, protective measures, home care, long term care, clinical care etc. The health department should provide training for Capacity building \& awareness among healthcare workers to protect themselves \& Creating awareness particularly about good nutrition and sleep which often remain neglected.

- There should be reasonable working hours of HCWs as per health facilities. Workers of Health facilities having heavy workload and more number of patients should have reduced working hours and more HCWs to work in different small shifts and vice versa.

- Responsibilities \& protection of healthcare workers with legal acts like Epidemic disease act and various labour laws, ward and workplace protection should be considered \& modified as per situation to address vulnerability of workers to occupational, social, financial, mental, and physical with other recognized and non-recognized hazards added with providing a safe and protective working environment with nil corrupt and illegal practices.

- Active participation of workers of health task force from all categories is required in development and implementation of safety and health policies with continuous monitoring and evaluation of effectiveness of protocols and guidelines related to safety in order to modify if required at any stage of the cycle of safety operations. See figure1.

- The Government should establish quick grievance Redressal cell exclusively for healthcare workers with transparency and nil corrupt practices.

- Considering the healthcare \& population ratio to divert load as well as considering fact that loss of one healthcare worker is going to reduce the health coverage of population and will put more stress on already overstressed health system.

- The agent virus of SARS-CoV-2 is changing continuously and virulence and case fatality rates are also changing accordingly. Keep everyone aware of global and local scenario by establishing communication channels with healthcare workers exclusively to avoid panic and misinformation.

- Reservation of special beds for healthcare workers on priority basis added with proper treatment especially senior healthcare workers and workers vulnerable due to co morbidities due to pre-existing health conditions/illnesses such as hypertension, DM, COPD, AID etc.

\section{Protective Methods should be applied to reduce mortality and morbidity of HCWs such as:}

- Provide proper, timely information and capacity building among healthcare personals for being prepared for self protection and testing if required, addressing the fact that an infected symptomatic/asymptomatic healthcare personal can spread the infection to colleagues, household members, public as well as non infected patients of NCD etc.

- Establish and implement using regular guidelines of wearing proper mask of safety standards as well as changing it as per guidelines, other PPEs, social distance when possible, WASH guidelines for 
sanitation-hygiene, good nutrition, proper sleep and stress reducing measures, sanitizer or soap use as per availability. Infection control training must be provided to all HCWs. Must know steps and order of wearing and removing personal safety gears - see Table 2 Applying different level of protection for HCWs working in different settings see Table 1

- Avoid touching source of entry of covid-19 i.e. eye, nose, mouth during working hours at hospital and if possible after duty too. Inform timely if you have symptoms and with isolation take proper treatment as per standard guidelines. During isolation don't forget to disinfect cloth etc. Nutrition is very important to help body have sufficient energy to fight hence have a proper balance diet with special recommendations. If you are not expert avoid self medication and contact expert.

- Maintain daily disinfection of all surfaces of hospital area with disinfectants. The virus may persist on surface for several hours. For ward protection divide ward in different areas - see

Figure2Conceptual scheme of workplace protection for healthcare workers (HCWs). The green arrows show the direction of movement of the HCWs; the red arrows show the direction of movement of the coronavirus disease 2019 (COVID-19) patients. The entrances to all rooms were marked with specific signs warning the HCWs to move in the right direction.

- Patients testing positive for COVID-19 were directed to the quarantine ward/ICU/other wards as per triage considerations they were placed in different isolation rooms/wards for further treatment. The clean area comprised the office where the medical staff worked, and measures were taken to prevent the virus from entering this area. The disinfection room was the place where the HCWs disinfected their personal belongings (cell phone, watch, and so on) and performed hand hygiene. The preparation room was the place where the HCWs dressed in appropriate personal protective equipment (PPE). The negative pressure operating room was designated for the surgical treatment of COVID-19 patients, and it is an effective measure to control the source of infection and block the route of transmission.

- Rapid identification and isolation of covid-19 cases to ensure symptomatic workers are not in public places, relaxing room/waiting rooms, reception areas, emergency departments or other common places used by healthy workers. Fresh joining health worker history of travel etc and test must be done for covid-19 before joining for isolating infectious cases.

- Gathering at workplace should be avoided to reduce potential of exposure. Contact tracing of cases at workplace, containment, education, communication for mitigation of further problems. Restriction on public events like birthday etc at workplace. See figure 4-source WHO (world health organisation)

- Proper ventilation, plastic shields, sneeze guards, masks, N-95, respirators as per need of the work with training and drills.

- Allow sick worker to stay home and limit number of staff present for high potential exposure tasks. Period check up of health workers for assessing physical, mental and social well being should be done on routine basis.

- Protection of workers right such as safety standards, regular supply of PPE etc. 
Key questions does the work setting require close contact with covid-19 infected confirmed cases? Do specific job duties require close repeated or extended period of contact with covid-19 cases? Is there community spread of the virus in the workplace? Will a worker paid if quarantined? What can be done for workers who have no paid sick leave? How to ensure free of cost treatment to healthcare workers particularly having low wages when government have fixed daily treatment cost at several thousand per day in private facilities? What Other impacts on HCWs \& family? Why the expired healthcare workers families have not yet received the benefits announced by the government?

- HCWs with high potential for exposure- covid-19 ward duty, laboratories testing covid-19 samples, autopsy work, bronchoscopy, sputum induction, dental procedures of covid-19 cases, aerosol generating procedures, ambulance workers carrying covid-19 cases and dead bodies of covid-19 patients, housekeeping workers of covid-19 wards and ICU facilities should be protected at any cost to ensure the continuous delivery of health services.

\section{Conclusion}

- There is no proper data available regarding actual count of mortality and morbidity of HCWs till date and even the government admit this fact."Health is a state subject. Such data is not kept at the Central level. However, it is maintained at the national level under the PM scheme," Central Health Minister of India Harsh Vardhan told[i]

- Investigate and observe healthcare worker having signs and symptoms of covid-19 as well as cases having potential exposure within 14 days before onset of symptoms. Keep these in suspected cases list.

- Triage of Health workers as per laboratory confirmed and suspected cases, mild/moderate / severe cases and provide treatment as per prescribed latest guidelines.

- Vaccination of healthcare workers on priority basis with due consideration to efficacy and effectiveness of vaccines.

- Maintaining critical utililities and infrastructure is necessary to provide adequate treatment as well as rostering personnel according to requirements keeping reserve for future.

- Supportive policy and communication to ensure continuum of activities and services. Stocking supplies and using multiple suppliers to ensure continuity of operations.

- Covid-19 workplace plan should be made with management leadership with hazard identification and risk assessment. Strategy for hazard prevention and control, risk communication, education, training, system evaluation and improvement etc should be implemented.

- Special precaution for healthcare elderly workers and those with pre-existing health conditions and co morbidities

- With the rapid spread of COVID-19, the healthcare systems \& HCWs are facing severe burdens.

- A large number of medical staffs are infected due to the lack of adequate protection. 
Currently, the COVID-19 pandemic is growing day by day with lack of essential facilities for treatment. Some experts have warned of a possible third wave of COVID-19.

- In the long run, proper protection from contracting COVID-19 in clinics/opd/ipd and hospitals is necessary and should be made norm. The protection of HCWs and appropriate training are of paramount importance in the fight against COVID-19 pandemic.

- Even the court in India seems to disagree over data presented by government on mortality and morbidity.[ii]

[i]https://www.tribuneindia.com/news/nation/no-data-of-dead-healthcare-staff-harsh-vardhan-141719

[ii]https://scroll.in/latest/995184/covid-19-patna-hc-pulls-up-bihar-officials-for-submitting-differing-dataon-toll-warns-of-action

\section{Declarations}

-This paper has not been previously published and is not currently under consideration by another journal. The document is Microsoft word with English (India) language \& 5512 words Total.

\section{-Ethics approval and consent to participate:}

Not applicable. This study has not involved any human or animals in real or for experiments

-Consent for publication: Not applicable

-Availability of data and materials: The data \& materials for study is mentioned as references

\section{-Conflicts of Interest/ Competing Interest}

There are no conflicts / competing of interest

- Funding-Self sponsored. No aid taken from individual or agency etc.

- Authors' contributions: The whole work is solely done by the Author - Dr Piyush Kumar,

- Authors' qualification: M.B.B.S. - Sri Krishna Medical College, EMOC- PMCH

- Authors' affiliations: General Medical Officer- Bihar Health Services- Government of Bihar,

- Acknowledgements- I am thankful to Advocate Anupama my wife for cooperation.

- Author information: The author is currently working as general medical officer for the government of Bihar.

-Financial Support \& sponsorship: Nil 


\section{References}

1. https://www.ndtv.com/india-news/244-doctors-died-since-april-1-in-covid-second-wave-50-yesterday2443647

2. https://doi.org/10.22541/au.162083035.55581251/v1

3. https://www.telegraphindia.com/india/bihar-doctor-deaths-blamed-on-inferior-ppe/cid/1788730

4. https://covidscholar.org/article/608d13484e85066fbf2f1797

5. https://doi.org/10.21203/rs.3.rs-348841/v4

6. https://www.researchsquare.com/article/rs-360551/v1

7. https://www.euro.who.int/en/countries/albania/news/news/2021/3/women-at-the-forefront-of-thecovid-19-response-in-albania-we-will-keep-fighting-until-this-virus-is-defeated

8. https://europepmc.org/article/ppr/ppr304897

9. https://www.nytimes.com/2021/05/18/world/asia/india-covid-doctors-medical-workers.html

10. https://scroll.in/article/992634/amidst-intense-covid-19-second-wave-indian-government-insurancecover-for-health-workers-has-lapsed

11. https://pib.gov.in/PressReleasePage.aspx?PRID=1654454

12. https://www.tribuneindia.com/news/nation/no-data-of-dead-healthcare-staff-harsh-vardhan-141719

13. https://scroll.in/latest/995184/covid-19-patna-hc-pulls-up-bihar-officials-for-submitting-differingdata-on-toll-warns-of-action

14. https://doi.org/10.1016/J.IJID.2020.10.064

\section{Tables}

Due to technical limitations, tables are available as downloads in the supplementary files section.

\section{Figures}




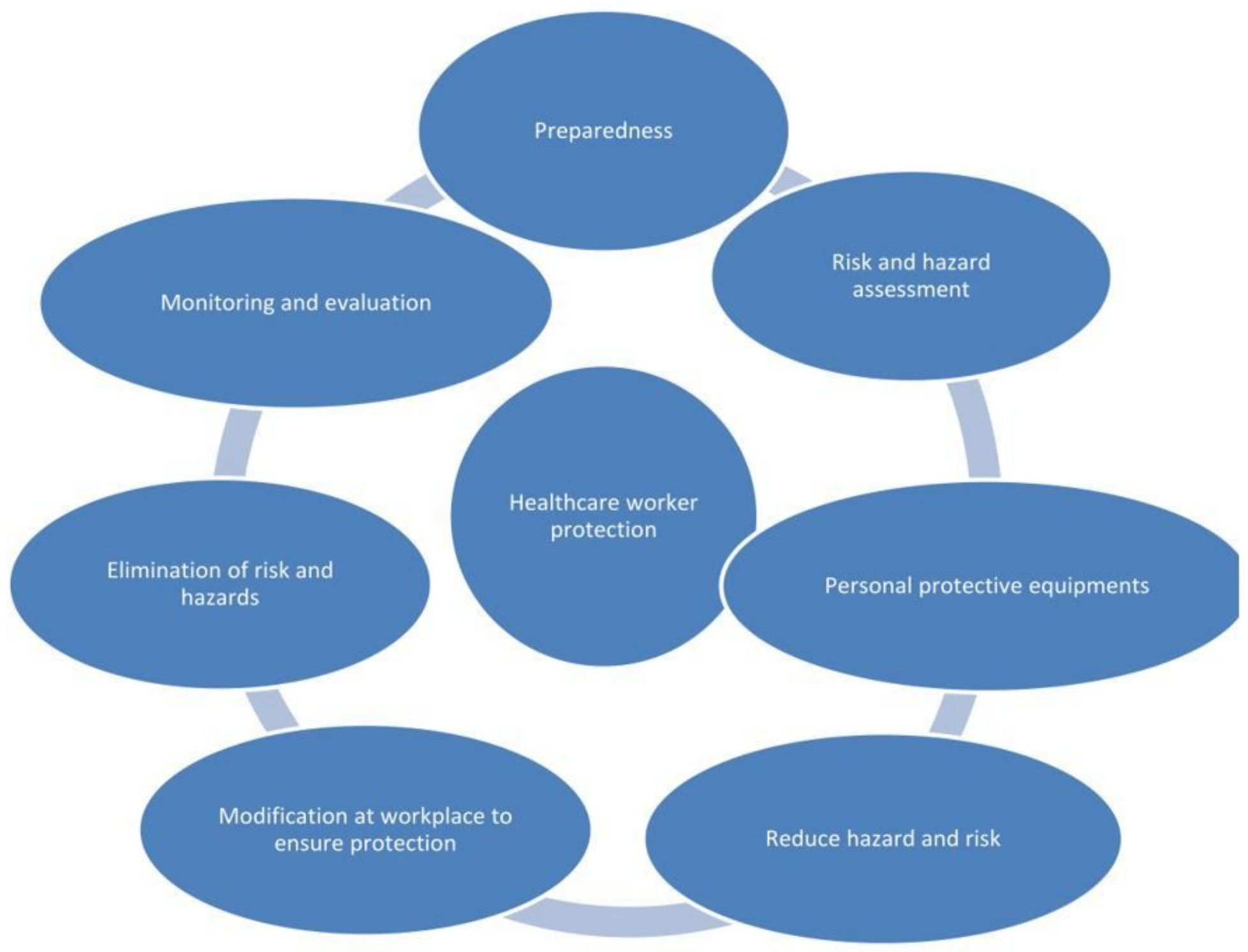

Figure 1

Monitoring and evaluation of effectiveness of protocols and guidelines 


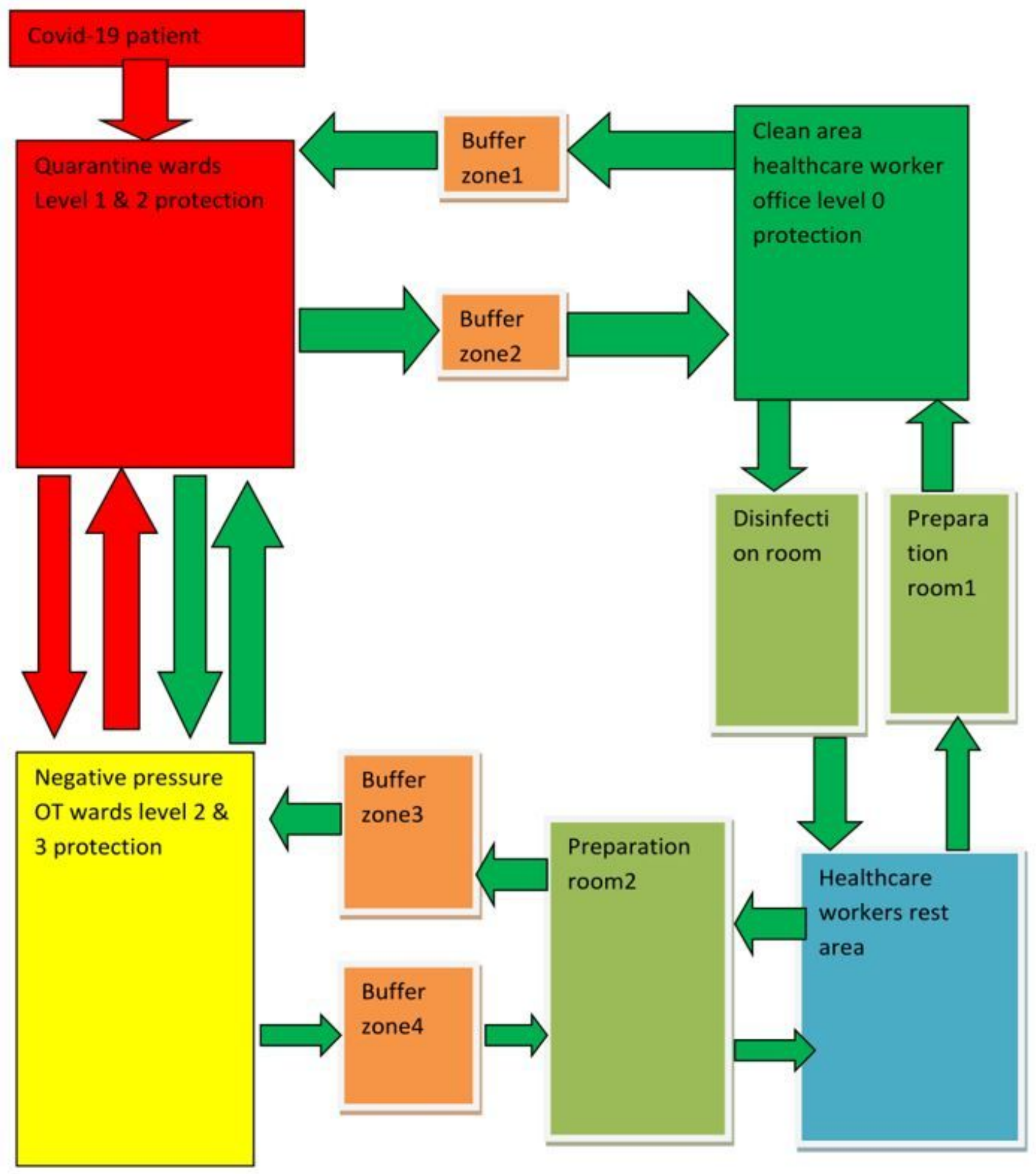

Figure 2

Ward protection - divide ward in different areas \& apply different levels of protection 


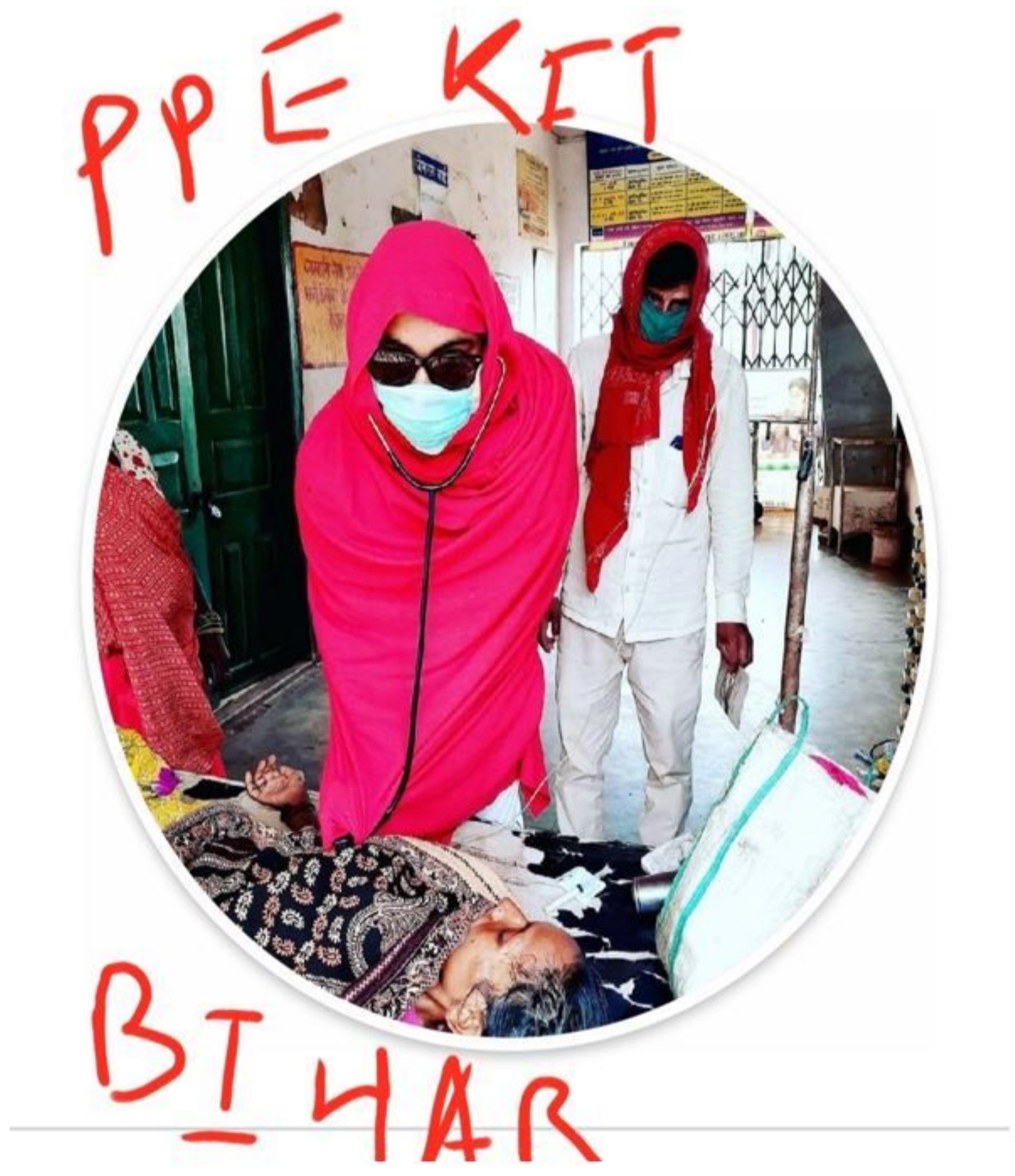

Figure 3

A HCW, India using bed sheet as ppe kit and personal goggles for protection. 


\section{FACTORS TO HELP YOU MAKE SAFER CHOICES}

WHEN YOU'RE IN AN AREA OF WIDESPREAD COVID-19 TRANSMISSION

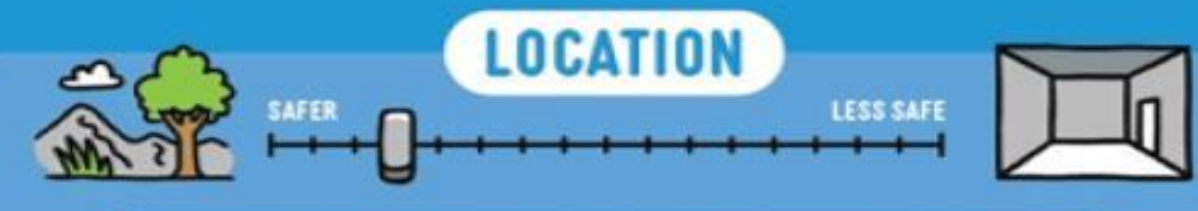

Open air spaces safer than enclosed spaces

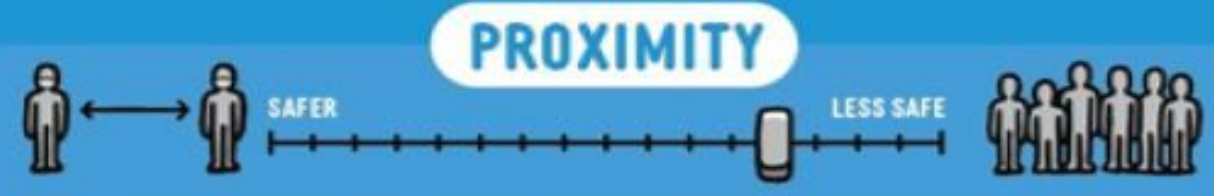

Farther away from others safer than close together

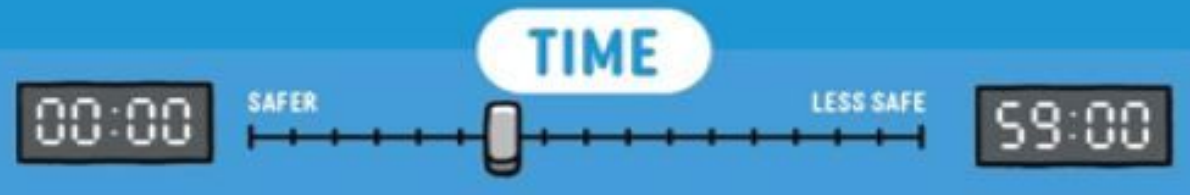

Shorter time periods with others are safer

REMEMBER, IT'S ALWAYS SAFER TO:

1.) iो 50 IDI

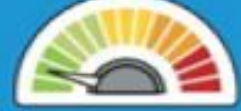

KNOW YOUR RISK.

LOWER YOUR RISK.

\section{Figure 4}

who-3-factors-poster to help you make safer choice when you are in an area of widespread covid-19 transmission.

\section{Supplementary Files}


This is a list of supplementary files associated with this preprint. Click to download.

- tables.docx 